\title{
A Three-Phase Interleaved Floating Output Boost Converter
}

\author{
Ajmal Farooq, Zeeshan Malik, Dongchang Qu, Zhaohui Sun, and Guozhu Chen
}

College of Electrical Engineering, Zhejiang University, Hangzhou 310027, China

Correspondence should be addressed to Ajmal Farooq; farooqaj@yahoo.com

Received 13 July 2015; Revised 12 October 2015; Accepted 15 October 2015

Academic Editor: Hossein Moayedi

Copyright (C) 2015 Ajmal Farooq et al. This is an open access article distributed under the Creative Commons Attribution License, which permits unrestricted use, distribution, and reproduction in any medium, provided the original work is properly cited.

\begin{abstract}
High step-up dc-dc converter is an essential part in several renewable energy systems. In this paper, a new topology of step-up dc-dc converter based on interleaved structure is proposed. The proposed converter uses three energy storing capacitors to achieve a high voltage gain. Besides the high voltage gain feature, the proposed converter also reduces the voltage stress across the semiconductor switches. This helps in using low rating switching devices which can reduce the overall size and cost of the converter. The operating principle of the proposed converter is discussed in detail and its principle waveforms are analyzed. An experiment is carried out on a $20 \mathrm{~V}$ input, $130 \mathrm{~V}$ output, and $21 \mathrm{~W}$ power prototype of the proposed converter in the laboratory to verify the performance of the proposed converter. An efficiency of $91.3 \%$ is achieved at the rated load.
\end{abstract}

\section{Introduction}

Several applications require high step-up dc-dc voltage conversion. One of the most common applications is the photovoltaic energy sources where the low input voltage should be stepped-up to high dc-link voltage. Other applications include fuel cell, hybrid electric vehicle (HEV), high-intensity discharge lamp ballasts, and uninterruptible power supplies. A high step-up dc-dc converter is essential for such kind of applications. For such type of high step-up dc-dc voltage conversion, a traditional boost converter shown in Figure 1 will operate at very high duty cycle (above $80 \%$ ) as the voltage gain of a simple boost converter is $1 / 1-D$. Such high duty cycle will cause severe reverse recovery problem of the output diode. Also the switches in the simple boost converter will experience a high voltage stress as their voltage stress is equal to the output voltage. Moreover, it needs large filter elements to minimize the ripples as it has only one inductor with no ripple cancellation. For this purpose, various high step-up topologies have been reported in the literature [1-3].

Two-stage/quadratic boost converter comprising two boost converters can be used to achieve high voltage gain as the voltage gain is equal to the product of the gains of two boost converters, that is, $1 /(1-D)^{2}$. However, using two boost converters may degrade the overall efficiency as the overall efficiency is also equal to the product of the efficiencies of two boost converters [4-6]. Inductorless switched capacitor circuits can give high step-up voltage conversion ratio, but they use a large number of switches and gate drives. The efficiency of switched capacitor circuit also is poor $[7,8]$. Interleaved or parallel structure is well known for reducing the ripples due to its well-known feature of ripple cancellation among the phases. Moreover, it can handle more power, but it does not help in increasing the step-up voltage gain or reducing the voltage stress on switches [9].

Tapping among the inductors and coupling of various inductors can achieve high step-up voltage conversion ratio by adjusting the turn ratio. However, it is very difficult to perfectly couple inductors and the existence of leakage inductance can create problems of large voltage overshoots [10-14]. Boost converter employing voltage multiplier and three-state switching cells can achieve high voltage gain and also reduces ripple in input current. But the voltage gain of one multiplier cell is not much high and for a very high stepup voltage conversion more numbers of multipliers cells will be needed $[15,16]$. Isolated converters such as half-bridge, full-bridge, and flyback can achieve high step-up voltage conversion by adjusting the turn ratio of the transformer. But 


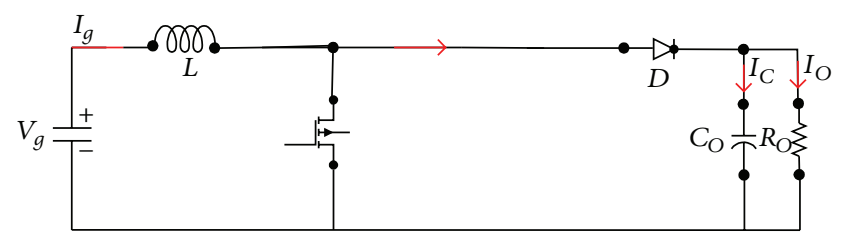

FIGURE 1: Circuit diagram of traditional boost converter.

they have their own problems related to transformers and are more expensive as compared to nonisolated types [17].

To achieve high voltage gain and lower switch stress, a new topology of dc-dc converter is presented in this paper. The circuit diagram is shown in Figure 2. The proposed converter is a three-phase interleaved boost converter with an intermediate capacitor and two output capacitors which forms the floating output. The proposed converter can achieve a very high voltage gain as well as reduce the voltage stress of switches.

\section{Operating Principle of the Proposed Converter}

Figure 2 shows the circuit diagram of the proposed converter. It consists of three phases with $L_{1}$ being the filtering inductor of phase $\# 1, L_{2}$ being the inductor of phase $\# 2$, and $L_{3}$ being the filtering inductor of phase \#3. Transistors $S_{1}, S_{2}$, and $S_{3}$ are the main switches of phase \#1, phase \#2, and phase $\# 3$, respectively. Similarly, $D_{1}, D_{2}$, and $D_{3}$ are the rectifying diodes of three phases. $V_{S}$ is the supply voltage, $V_{O}$ is the output voltage, and $R_{L}$ is load resistor. For the analysis of the proposed converter the following assumptions are made:

(i) $L_{1}=L_{2}=L_{3}=L$ (where $L$ is the inductance/phase),

(ii) $C_{1}=C_{2}=C$ (where $C$ is the filter capacitor),

(iii) all capacitors and inductors are very large, so that their ripples are very small,

(iv) the converter always operates in continuous conduction mode (CCM).

The operation of the converter is done at a fixed switching frequency $F_{S}$ and it has a fixed switching period of $T_{S}$. The operation is such that switches $S_{1}, S_{2}$, and $S_{3}$ are turned on and off by two PWM signals which is 180 -degree phase shifted. One PWM signal is applied to the gate of $S_{2}$ and another PWM signal which is 180-degree phase shifted from the first one is applied to the gates of $S_{1}$ and $S_{3}$. There is no phase shift between phase \#1 and phase \#3 and both these phases are at 180 -degree phase shift with phase \#2. The converter is analyzed for a duty cycle $D$ greater than $50 \%$. There are total four switching states in one switching period. Figure 3 shows the circuit diagram of the proposed converter formed in each state and Figure 4 shows steady state waveforms for the proposed converter.

State-I $\left(t_{O} \leq t \leq t_{1}\right)$. State-I starts at $t=t_{O}$ when all the transistors $S_{1}-S_{3}$ are turned on. During this state all the diodes $D_{1}-D_{3}$ remain off. Figure 3(a) shows the circuit topology of the proposed converter formed in this state. Inductors $L_{1}, L_{2}$, and $L_{3}$ get charged by the supply voltage $V_{S}$ and the currents $I_{1}, I_{2}$, and $I_{3}$ through them increase with slopes of $V_{S} / L$. Capacitor $C_{\text {in }}$ is disconnected from the supply as well as from the load; it neither charges nor discharges and its voltage $V_{C_{\text {in }}}$ is constant. Both the output capacitors $C_{1}$ and $C_{2}$ discharge to the load and their voltages $V_{C_{1}}$ and $V_{C_{2}}$ fall with slopes of $-V_{O} /\left(R_{L} C\right)$.

State-II $\left(t_{1} \leq t \leq t_{2}\right)$. State-II begins when switches $S_{1}$ and $S_{3}$ are turned off at $t=t_{1}$. The switch $S_{2}$ is still on. Diodes $D_{1}$ and $D_{3}$ start conducting, whereas diode $D_{2}$ is still off. Figure $3(\mathrm{~b})$ shows the circuit topology formed in this state. Inductor $L_{2}$ is still in charging mode and its current $I_{2}$ rises with a slope of $V_{S} / L$. Inductors $L_{1}$ and $L_{3}$ are in discharge modes and their currents $I_{1}$ and $I_{3}$ fall with slopes of $\left(V_{S}-V_{C_{\text {in }}}\right) / L$ and $\left(V_{S}-V_{C_{2}}\right) / L$, respectively. Capacitor $C_{1}$ is still in discharge mode and its voltage $V_{C_{1}}$ is still decreasing with same slope of $-V_{O} /\left(R_{L} C\right)$. Capacitors $C_{\text {in }}$ and $C_{2}$ are charged up by the supply and their voltages $V_{C_{i}}$ and $V_{C_{2}}$ rises with slopes of $I_{1} / C_{\text {in }}$ and $I_{3} / C-V_{O} /\left(R_{L} C\right)$. This state ends at $t=t_{2}$.

State-III $\left(t_{2} \leq t \leq t_{3}\right)$. This state is similar to state-I. Again all the transistors are on and all the diodes are off. The circuit diagram is the same as in state-I (Figure 3(a)).

State-IV $\left(t_{3} \leq t \leq t_{4}\right)$. This state begins when switch $S_{2}$ is turned off at $t=t_{3}$. Switches $S_{1}$ and $S_{3}$ are still off. Diode $D_{2}$ starts conducting and diodes $D_{1}$ and $D_{3}$ remain off. Figure 3(c) shows the circuit topology formed in this state. Inductors $L_{1}$ and $L_{3}$ are charged by the supply and their currents $I_{1}$ and $I_{3}$ rise with slopes of $V_{S} / L$. Inductor $L_{2}$ discharges and its current $I_{2}$ decreases with a slope of $\left(V_{S}+\right.$ $\left.V_{C_{\text {in }}}-V_{C_{1}}\right) / L$. Capacitor $C_{\text {in }}$ discharges to load and its voltage $V_{C_{\text {in }}}$ falls with a slope of $-I_{2} / C_{\text {in }}$. Capacitor $C_{1}$ gets charged and its voltage $V_{C_{1}}$ rises with a slope of $I_{2} / C-V_{O} /\left(R_{L} C\right)$. Capacitor $\mathrm{C}_{2}$ also discharges to load and its voltage falls with a slope of $-V_{O} /\left(R_{L} C\right)$. This state ends at $t=t_{4}$.

\section{Steady State Analysis of the Proposed Converter}

To simplify the analysis of the proposed converter, the time of each state is expressed in terms of duty cycle $D$ and switching period $T_{S}$ as

$$
\begin{aligned}
& t_{\mathrm{O}}=0 \mathrm{sec}, \\
& t_{1}=\left(D T_{S}-\frac{T_{S}}{2}\right) \mathrm{sec}, \\
& t_{2}=\frac{T_{S}}{2} \mathrm{sec}, \\
& t_{3}=D T_{S} \mathrm{sec}, \\
& t_{4}=T_{S} \mathrm{sec} .
\end{aligned}
$$

3.1. DC Conversion Ratio. For the voltage conversion ratio $M$ of the proposed converter we will apply the principle of 


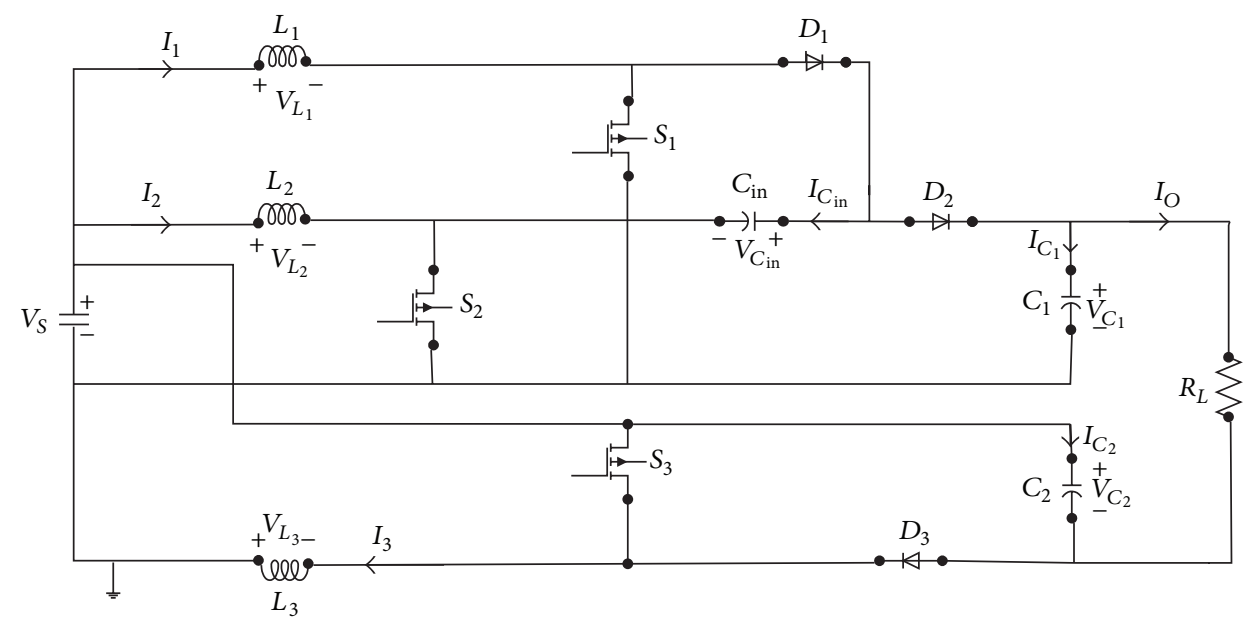

Figure 2: Circuit diagram of the proposed converter.

inductor volt second balance (VSB) on inductors $L_{1}, L_{2}$, and $L_{3}$. By VSB of inductor $L_{1}$ we get

$$
\begin{gathered}
V_{S}\left(t_{1}-t_{O}\right)+\left(V_{S}-V_{C_{\text {in }}}\right)\left(t_{2}-t_{1}\right)+V_{S}\left(t_{3}-t_{2}\right) \\
+V_{S}\left(t_{4}-t_{3}\right)=0 .
\end{gathered}
$$

The solution of (2) gives

$$
V_{C_{\text {in }}}=\frac{V_{S}}{(1-D)} .
$$

By VSB of inductor $L_{2}$ we get

$$
\begin{gathered}
V_{S}\left(t_{1}-t_{\mathrm{O}}\right)+V_{S}\left(t_{2}-t_{1}\right)+V_{S}\left(t_{3}-t_{2}\right) \\
+\left(V_{S}+V_{C_{\text {in }}}-V_{C_{1}}\right)\left(t_{4}-t_{3}\right)=0 .
\end{gathered}
$$

The solution of (4) gives

$$
V_{C_{1}}=\frac{V_{S}}{(1-D)}+V_{C_{\text {in }}}
$$

From (3) and (5) we get

$$
V_{C_{1}}=\frac{2 V_{S}}{(1-D)}
$$

By VSB of inductor $L_{3}$ we get

$$
\begin{gathered}
V_{S}\left(t_{1}-t_{O}\right)+\left(V_{S}-V_{C_{2}}\right)\left(t_{2}-t_{1}\right)+V_{S}\left(t_{3}-t_{2}\right) \\
+V_{S}\left(t_{4}-t_{3}\right)=0 .
\end{gathered}
$$

The solution of (7) gives

$$
V_{C_{2}}=\frac{V_{S}}{(1-D)} .
$$

The output capacitors $C_{1}$ and $C_{2}$ remain in series with the supply voltage $V_{S}$ and therefore the output voltage $V_{O}$ of the proposed converter is given by

$$
V_{O}=V_{C_{1}}+V_{C_{2}}-V_{S}
$$

By (6), (8), and (7) we get

$$
V_{O}=\left\{\frac{(2+D)}{(1-D)}\right\} V_{S}
$$

And the voltage conversion ratio $M$ is

$$
M=\frac{V_{O}}{V_{S}}=\frac{(2+D)}{(1-D)} .
$$

3.2. Voltage Stress of Semiconductor Devices. Switches $S_{1}$ and $\mathrm{S}_{3}$ are off in state-II and remain on in the rest of switching period. Referring to Figure 3(b), the off-state voltage (voltage stress) of switches $S_{1}$ and $S_{2}$ can be obtained as

$$
\begin{aligned}
& V_{S_{1}}=V_{C_{\text {in }}}=\frac{V_{S}}{(1-D)}, \\
& V_{S_{2}}=V_{C_{1}}-V_{C_{\text {in }}}=\frac{V_{S}}{(1-D)} .
\end{aligned}
$$

Switch $S_{2}$ is off only in state-IV. Referring to Figure 3(c) the voltage stress $V_{S_{3}}$ of switch $S_{3}$ is given by

$$
V_{S_{3}}=V_{C_{2}}=\frac{V_{S}}{(1-D)}
$$

In similar way the maximum voltage drop (voltage stress) of the diodes $D_{1}, D_{2}$, and $D_{3}$ can be found out and is given by

$$
\begin{aligned}
& V_{D_{1}}=-V_{C_{1}}=-\frac{2 V_{S}}{(1-D)}, \\
& V_{D_{2}}=-V_{C_{2}}+V_{C_{\text {in }}}=-\frac{V_{S}}{(1-D)}, \\
& V_{D_{3}}=V_{C_{2}}=\frac{V_{S}}{(1-D)} .
\end{aligned}
$$

3.3. Ripple Current and Ripple Voltage. Referring to Figure 4, the peak to peak ripple $\Delta i_{1}$ in the current $I_{1}$, peak to peak 


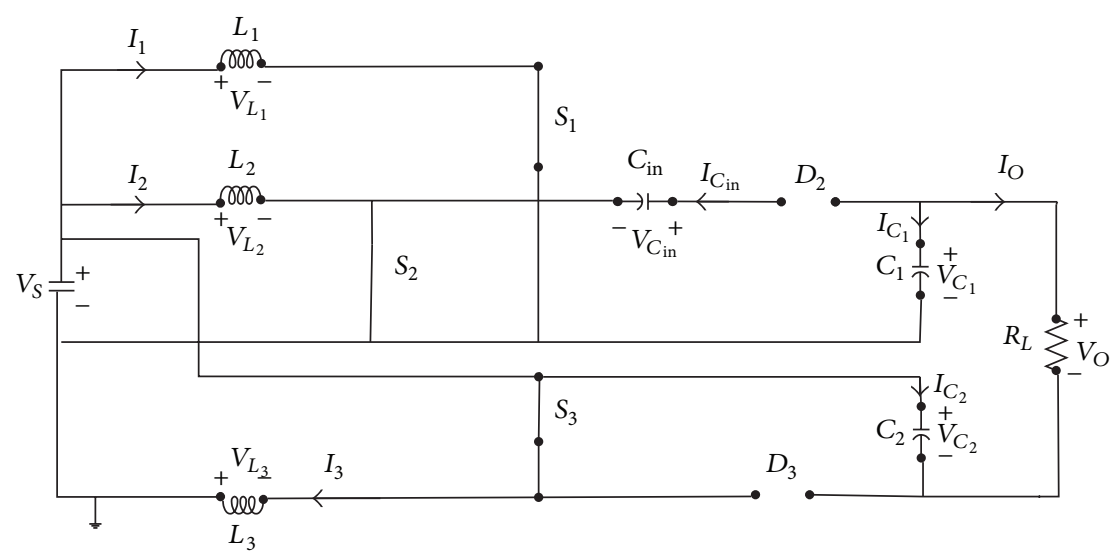

(a)

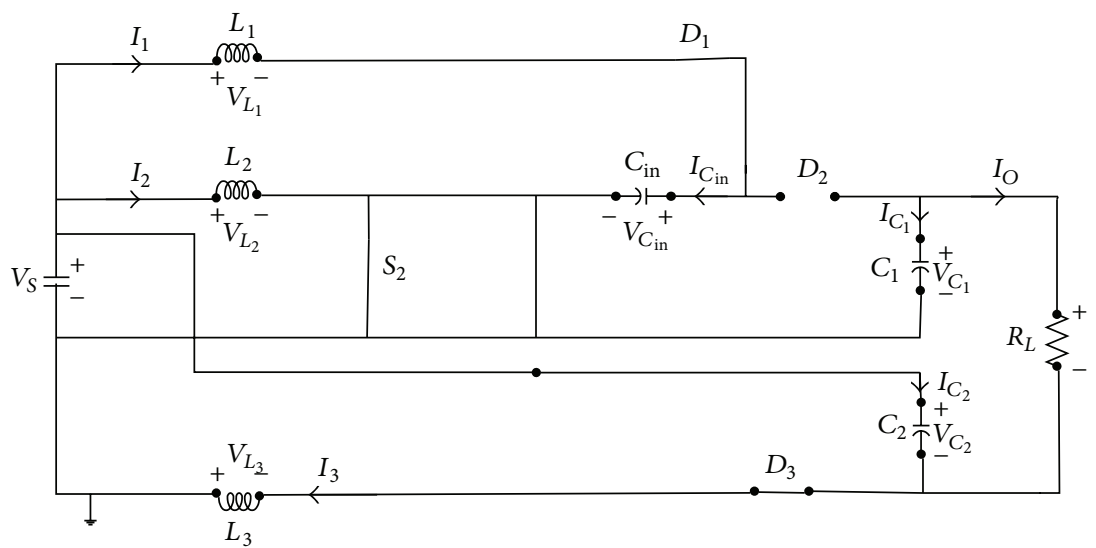

(b)

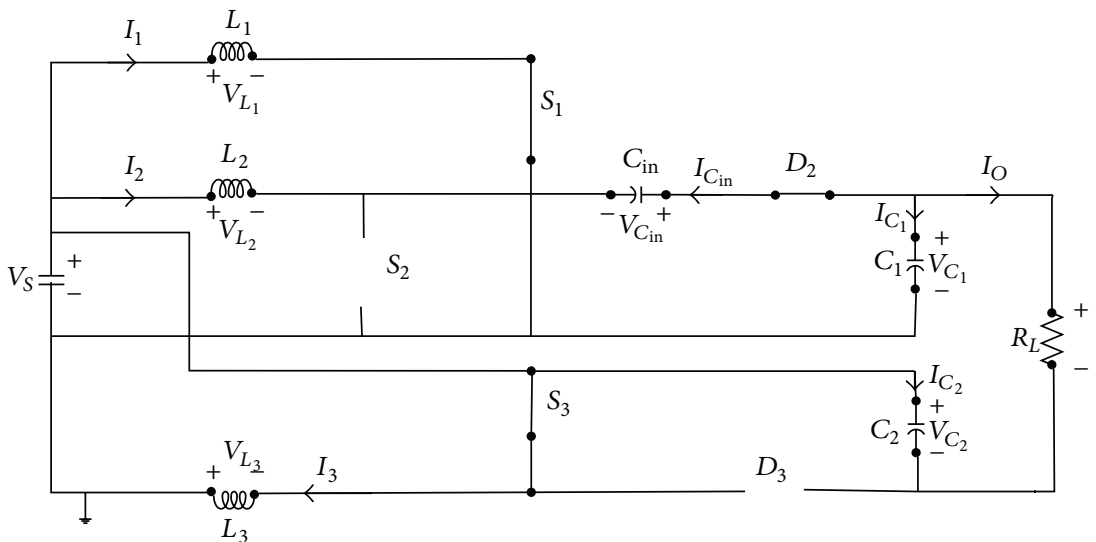

(c)

Figure 3: Operating circuits of the proposed converter. (a) State-I and state-III, (b) state-II, and (c) state-IV.

ripple $\Delta i_{2}$ in current $I_{2}$, and peak to peak ripple $\Delta i_{3}$ in current $I_{3}$ are expressed as
Similarly, the peak to peak ripple $\Delta V_{C_{\text {in }}}$ in voltage $V_{C_{\text {in }}}$ can be expressed as

$$
\Delta i_{1}=\Delta i_{2}=\Delta i_{3}=\frac{\left(D V_{S}\right)}{\left(L F_{S}\right)}
$$

$$
\Delta V_{C_{\text {in }}}=\frac{V_{O}}{\left(R_{L} C_{\text {in }} F_{S}\right)} .
$$




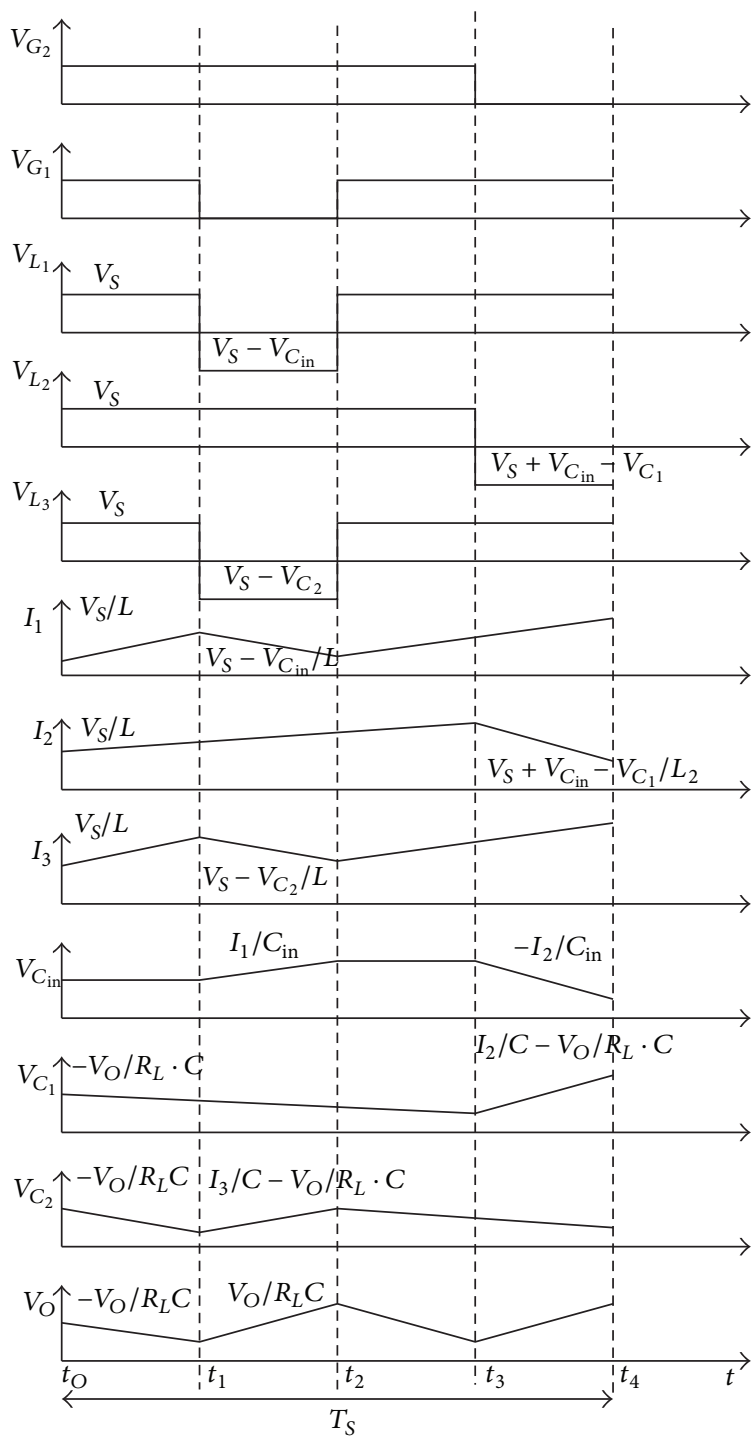

FIGURE 4: Steady state waveforms of the proposed converter.

The peak to peak ripple $\Delta V_{C_{1}}$ in voltage $V_{C_{1}}$ and $\Delta V_{C_{2}}$ in voltage $V_{C_{2}}$ are given by

$$
\Delta V_{C_{1}}=\Delta V_{C_{2}}=\frac{\left(D V_{O}\right)}{\left(R_{L} C F_{S}\right)}
$$

The peak to peak ripple $\Delta V_{O}$ in the output voltage $V_{O}$ is given by

$$
\Delta V_{O}=\left\{(2 D-1) V_{O}\right\}\left(R_{L} C F_{S}\right) .
$$

\section{Experimental Results}

To verify the effectiveness of the proposed converter, the parameters listed in Table 1 are used to obtain the theoretical and experimental results of the proposed converter.
TABLE 1: Paramaters used for experiment.

\begin{tabular}{lcc}
\hline Name of parameter & Symbol & Value \\
\hline Output power & $P_{O}$ & $21[\mathrm{~W}]$ \\
Input voltage & $V_{S}$ & $20[\mathrm{~V}]$ \\
Output voltage & $V_{O}$ & $130[\mathrm{~V}]$ \\
Load resistance & $R_{L}$ & $800[\Omega]$ \\
Frequency & $F_{S}$ & $100[\mathrm{kHz}]$ \\
Filter inductor/phase & $L$ & $200[\mu \mathrm{H}]$ \\
Intermediate capacitor & $C_{\text {in }}$ & $1[\mu \mathrm{F}]$ \\
Output smoothing capacitor & $C$ & $1[\mu \mathrm{F}]$ \\
\hline
\end{tabular}

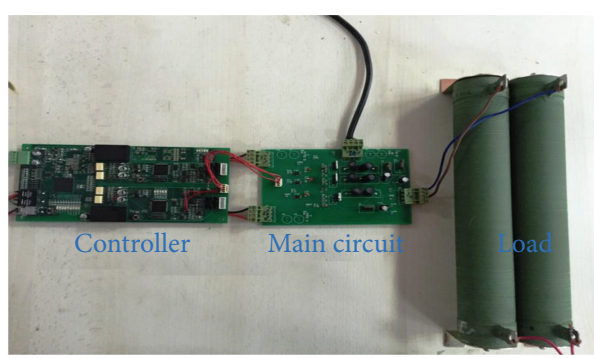

Figure 5: Photograph of prototype of the proposed converter.

Using (3), (6), (8), and (11) and using the parameters of Table 1, the following results are obtained:

$$
\begin{aligned}
D & =0.6, \\
V_{C_{\text {in }}} & =50 \mathrm{~V}, \\
V_{C_{1}} & =100 \mathrm{~V}, \\
V_{C_{2}} & =50 \mathrm{~V} .
\end{aligned}
$$

Similarly using the parameters of Table 1 in (12), (13), and (14) gives the voltage stress of semiconductor devices:

$$
\begin{aligned}
& V_{S_{1}}=50 \mathrm{~V}, \\
& V_{S_{2}}=50 \mathrm{~V}, \\
& V_{S_{3}}=50 \mathrm{~V}, \\
& V_{D_{1}}=-100 \mathrm{~V}, \\
& V_{D_{2}}=-50 \mathrm{~V}, \\
& V_{D_{3}}=-50 \mathrm{~V} .
\end{aligned}
$$

To verify the results and performance of the proposed converter an experiment has been carried out in the laboratory on a 21-watt prototype of the proposed converter using the parameters listed in Table 1. A photograph of the hardware of proposed converter is shown in Figure 5.

Figure 6 shows the experimental waveforms of the proposed converter for a duty cycle of $60 \%$. The gate signals $V_{G_{1}}$ and $V_{G_{2}}$ are shown in Figure 6(a). It can be seen that these two signals are at 180-degree phase shift with each other both have $60 \%$ duty cycle. Figure 6(b) shows the waveforms of input 


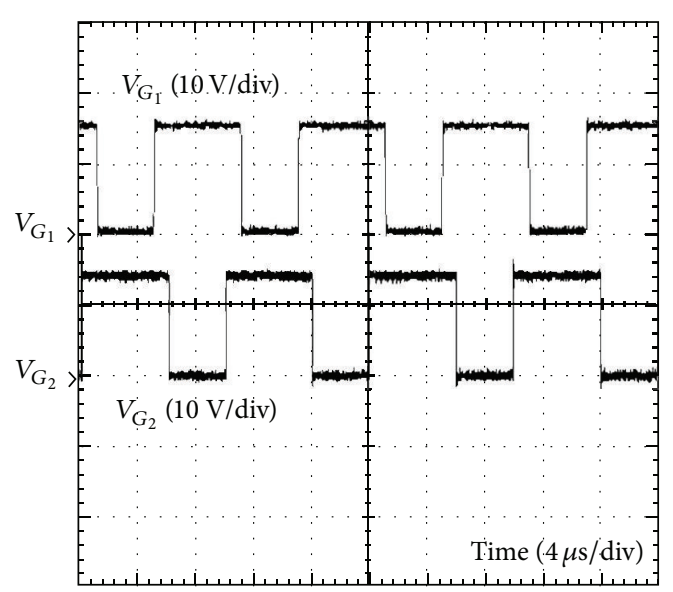

(a)

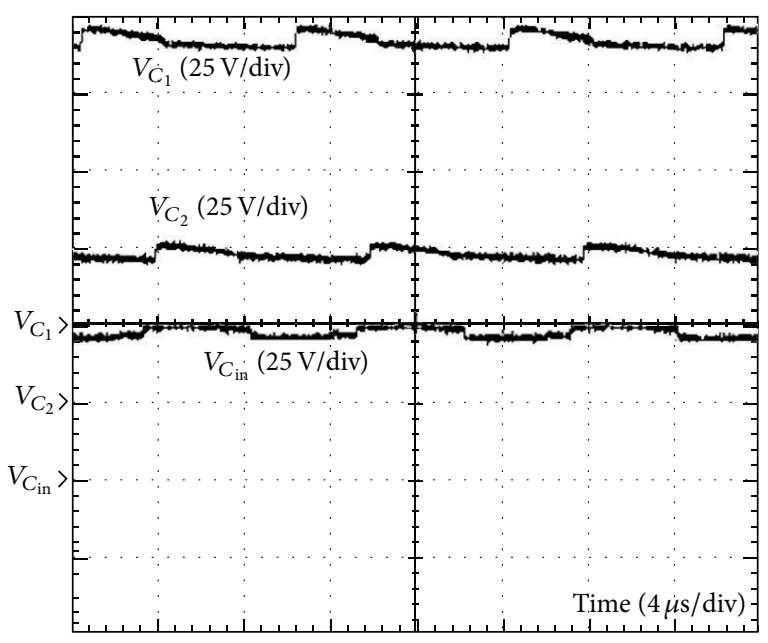

(c)

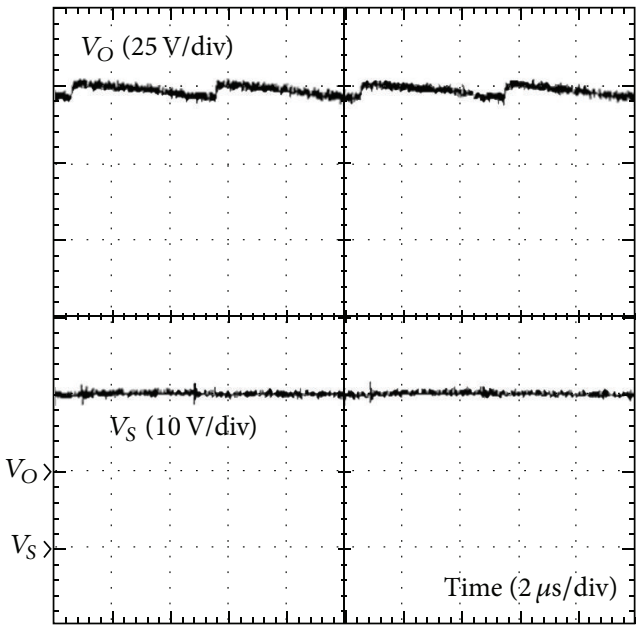

(b)

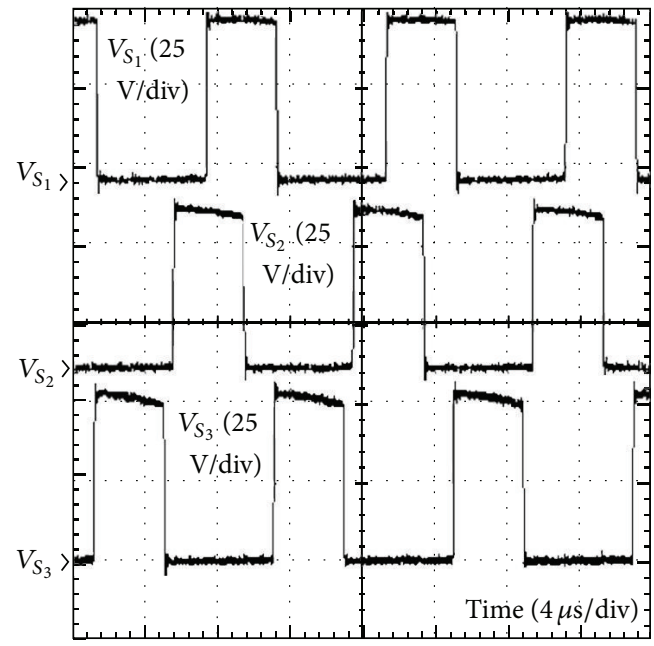

(d)

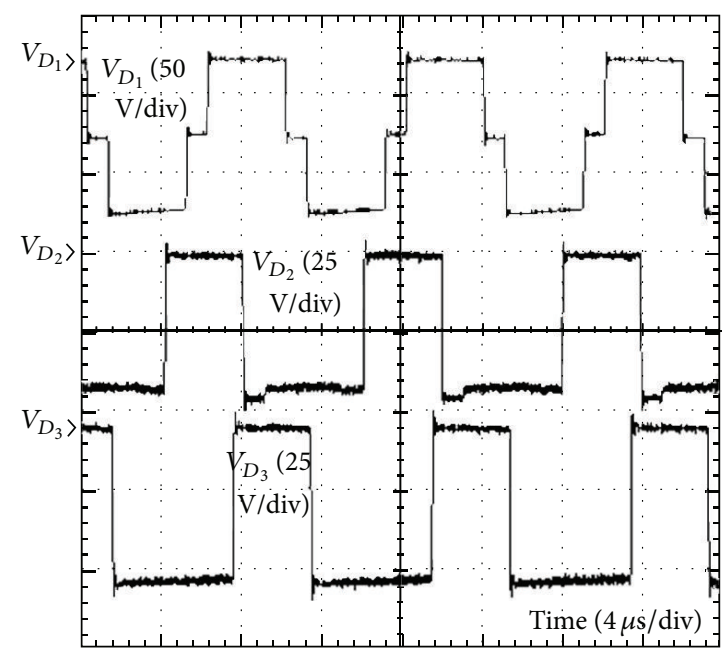

(e)

FIGURE 6: Experimental waveforms of the proposed converter. (a) Waveforms of PWM signals $V_{G_{1}}$ and $V_{G_{2}}$ with $60 \%$ duty cycle. (b) Waveforms of supply voltage $V_{S}$ and output voltage $V_{O}$. (c) Waveforms of voltages $V_{C_{1}}, V_{C_{2}}$, and $V_{C_{\text {in }}}$ across capacitors $C_{1}, C_{2} \& C_{\text {in }}$. (d) Waveforms of voltage stresses $V_{S_{1}}, V_{S_{2}}$ and $V_{S_{3}}$ of MOSFETs $S_{1}, S_{2}$, and $S_{3}$. (e) Waveforms of voltage stresses $V_{D_{1}}, V_{D_{2}}$, and $V_{D_{3}}$ of diodes $D_{1}, D_{2}$, and $D_{3}$. 
and output voltages of the proposed converter. As clear from Figure 6(b) the supply voltage $V_{S}$ to the proposed converter is 20 volts and the output voltage $V_{O}$ is 121.5 volts which is close to the ideal value of 130 volts. Thus the proposed converter is able to produce 130 volts output from 20 volts input at $60 \%$ duty cycle and easily achieves a step-up voltage conversion ratio of 6.5. Figure 6(c) shows the waveforms of the voltages across the capacitors $C_{1}, C_{2}$, and $C_{\text {in }}$. The voltage $V_{C_{1}}$ across capacitor $C_{1}$ is 93 volts and the voltage across each capacitor $C_{2}$ and $C_{\text {in }}$ is 47 volts which are also close to ideal/theoretically calculated values. The waveforms of the voltage stresses $V_{S_{1}}, V_{S_{2}}$, and $V_{S_{3}}$ across the MOSFETs $S_{1}, S_{2}$, and $S_{3}$ are shown in Figure 6(d). It can be seen that all the three voltages are equal to 50 volts. Thus the voltage stress across the MOSFETs is almost 2.6 times lower than the output voltage. Figure 6(e) shows the waveforms of the voltage stress across the diodes $D_{1}, D_{2}$, and $D_{3}$. As clear from Figure 6(e), the voltage stress $V_{D_{1}}$ across diode $D_{1}$ is -98 volts, the voltage stress $V_{D_{2}}$ across diode $D_{2}$ is -46 volts, and the voltage stress $V_{D_{3}}$ across diode $D_{3}$ is -48 volts. Thus the voltage stress across the diodes is also reduced considerably.

Traditional interleaved boost converters whether of two phases or three phases have step-up voltage conversion ratio of $1 /(1-D)$ and the voltage stress across their switches (transistors and diodes) is equal to the output voltage [18, 19]. Thus, for producing an output voltage of 130 volts from an input voltage of 20 volts, the traditional interleaved boost converter must operate at a duty cycle of $84.6 \%$ which is very high as compared to the proposed interleaved boost converter. Also for 130-volt output voltage, the voltage stress across the transistors and diodes of traditional interleaved boost converter will be 130 volts which is also very high as compared to the switch stresses of the proposed converter.

From experimental results, it is clear that the proposed converter has very good performance as compared to the traditional interleaved boost converter. It nearly produces 130 -volt output voltage from an input voltage of 16 volts with a duty cycle of $60 \%$ whereas the conventional interleaved boost converter will produce the same output at a duty cycle of $84.6 \%$ which is very high and can result in severe reverse recovery problems. Thus the proposed converter has considerably higher step-up voltage conversion ratio as compared to traditional interleaved boost converter and it easily overcomes the extreme high duty cycle operation and reverse recovery problem of the output diodes which appear in traditional interleaved boost converter. The voltage stress on the semiconductor devices of the proposed converter is also reduced considerably. Except the voltage stress of diode $D_{1}$ which is 100 volts, the voltage stress of all other switches in the proposed converter is 50 volts; thus low rating devices can be used which results in reducing the overall cost and size of the converter whereas the voltage stress of the switches of traditional interleaved boost converter is equal to the output voltage, that is, 130 volts. Thus the voltage stress across the switches of the proposed converter is 2.6 times lower than that across the switches of traditional interleaved boost converter.

Figure 7 shows a plot of experimentally measured efficiency of the proposed converter against the load. The load resistor is varied to change the power and efficiency is

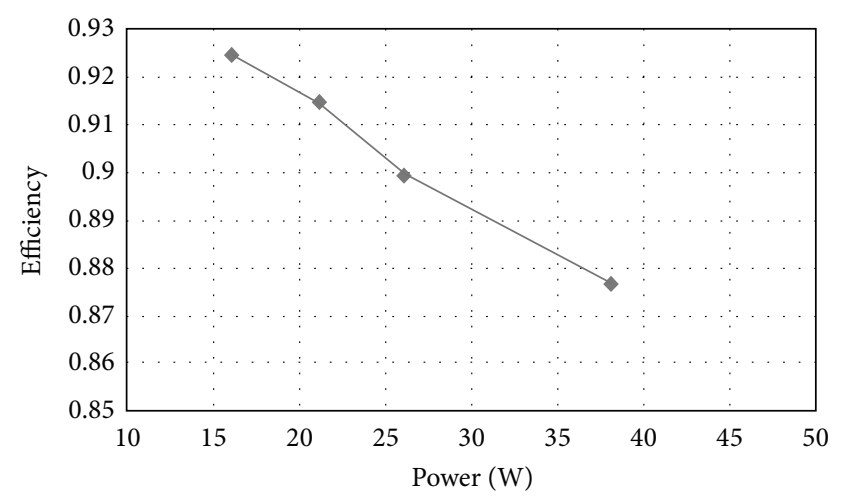

FIgURE 7: Experimentally measured efficiency of the proposed converter.

measured at different loads. An efficiency of $91.3 \%$ is achieved at the rated power of 21 watts and a maximum efficiency of $92.5 \%$ is achieved at 16 -watt output power. At 38 -watt output power, the efficiency is lowered to $87.7 \%$ due to increased conduction losses.

\section{Conclusion}

A new topology of interleaved boost converter is presented in this study. Besides the well-known feature of ripple reduction/cancellation of the interleaved converters, the proposed topology has several additional advantages over the traditional interleaved boost converter. The analysis shows that traditional interleaved boost converter will undergo high duty cycle operation and reverse recovery problem, whereas the proposed converter can achieve the same voltage gain at appropriate duty cycle. The voltage stress on switches of the proposed converter is $260 \%$ less than that of traditional interleaved boost converter. An efficiency of above $90 \%$ is achieved which is considered good. These features make the proposed converter a more suitable candidate for renewable energy generating system where high step-up $\mathrm{dc}-\mathrm{dc}$ voltage conversion is required.

\section{Conflict of Interests}

The authors declare that there is no conflict of interests regarding the publication of this paper.

\section{Acknowledgment}

The authors would like to thank the sponsorship of the National Science Foundation of China (NSFC) (no. 51177147).

\section{References}

[1] W. Li and X. He, "Review of nonisolated high-step-up DC/DC converters in photovoltaic grid-connected applications," IEEE Transactions on Industrial Electronics, vol. 58, no. 4, pp. 12391250, 2011.

[2] J. Dawidziuk, "Review and comparison of high efficiency high power boost DC/DC converters for photovoltaic applications," Bulletin of the Polish Academy of Sciences: Technical Sciences, vol. 59, no. 4, pp. 499-506, 2011. 
[3] Y. Hu, W. Cao, S. J. Finney, W. Xiao, F. Zhang, and S. F. McLoone, "New modular structure DC-DC converter without electrolytic capacitors for renewable energy applications," IEEE Transactions on Sustainable Energy, vol. 5, no. 4, pp. 1184-1192, 2014.

[4] R. Kadri, J.-P. Gaubert, G. Champenois, and M. Mostefai, "Performance analysis of transformless single switch quadratic boost converter for grid connected photovoltaic systems," in Proceedings of the 19th International Conference on Electrical Machines (ICEM '10), Rome, Italy, September 2010.

[5] Y.-M. Ye and K. W. E. Cheng, "Quadratic boost converter with low buffer capacitor stress," IET Power Electronics, vol. 7, no. 5, pp. 1162-1170, 2014.

[6] R. Haroun, A. El Aroudi, A. Cid-Pastor, and L. MartinezSalamero, "Sliding mode control of output-parallel-connected two-stage boost converters for PV systems," in Proceedings of the IEEE 11th International Multi-Conference on Systems, Signals \& Devices (SSD '14), pp. 1-6, IEEE, Barcelona, Spain, February 2014.

[7] O. Abutbul, A. Gherlitz, Y. Berkovich, and A. Ioinovici, "Stepup switching-mode converter with high voltage gain using a switched-capacitor circuit," IEEE Transactions on Circuits and Systems I: Fundamental Theory and Applications, vol. 50, no. 8, pp. 1098-1102, 2003.

[8] W. Qian, D. Cao, J. G. Cintrón-Rivera, M. Gebben, D. Wey, and F. Z. Peng, "A switched-capacitor DC-DC converter with high voltage gain and reduced component rating and count," IEEE Transactions on Industry Applications, vol. 48, no. 4, pp. 13971406, 2012.

[9] M. A. Devil, K. Valarmathi, and R. Mahendran, "Ripple current reduction in interleaved boost converter by using advanced PWM techniques," in Proceedings of the IEEE International Conference on Advanced Communication Control and Computing Technologies (ICACCCT '14), pp. 115-119, IEEE, Ramanathapuram, India, May 2014.

[10] Z. H. Shi, K. W. E. Cheng, and S. L. Ho, "Static performance and parasitic analysis of tapped-inductor converters," IET Power Electronics, vol. 7, no. 2, pp. 366-375, 2014.

[11] N. C. B. Ramos, M. T. Escoto Jr., and C. M. F. Odulio, "Design and analysis of an interleaved tapped-inductor boost converter for higher power and voltage gain applications," in Proceedings of the IEEE Region 10 Conference (TENCON '12), pp. 1-6, IEEE, Cebu, Philippines, November 2012.

[12] F. Yang, X. Ruan, Y. Yang, and Z. Ye, "Interleaved critical current mode boost PFC converter with coupled inductor," IEEE Transactions on Power Electronics, vol. 26, no. 9, pp. 2404-2413, 2011.

[13] M. Veerachary, T. Senjyu, and K. Uezato, "Maximum power point tracking of coupled inductor interleaved boost converter supplied PV system," IEE Proceedings: Electric Power Applications, vol. 150, no. 1, pp. 71-80, 2003.

[14] C. Feeney, C. Fitzgerald, and M. Duffy, "Investigation of coupled inductors in a phase interleaved boost module-integratedconverter," in Proceedings of the IEEE 5th International Symposium on Power Electronics for Distributed Generation Systems (PEDG '14), pp. 1-5, Galway, Ireland, June 2014.

[15] Y. J. A. Alcazar, R. T. Bascopé, D. S. De Oliveira Jr., E. H. P. Andrade, and W. G. Cárdenas, "High voltage gain boost converter based on three-state switching cell and voltage multipliers," in Proceedings of the 34th Annual Conference of the IEEE Industrial Electronics Society (IECON '08), pp. 2346-2352, Orlando, Fla, USA, November 2008.
[16] F. L. Tofoli, D. de Souza Oliveira Jr., R. P. Torrico-Bascopé, and Y. J. A. Alcazar, "Novel nonisolated high-voltage gain DC-DC converters based on 3SSC and VMC," IEEE Transactions on Power Electronics, vol. 27, no. 9, pp. 3897-3907, 2012.

[17] V. Vaisanen, [Performance and Scalability of Isolated Dc-Dc Converter Topologies in Low Voltage, High Current Applications [Ph.D. thesis], Lappeenranta University of Technology, Lappeenranta, Finland, 2012.

[18] A. Garrigós, J. M. Blanes, and J. L. Lizán, "Non-isolated multiphase boost converter for a fuel cell with battery backup power system," International Journal of Hydrogen Energy, vol. 36, no. 10, pp. 6259-6268, 2011.

[19] H. Xu, E. Qiao, X. Guo, X. Wen, and L. Kong, "Analysis and design of high power interleaved boost converters for fuel cell distributed generation system," in Proceedings of the 36th IEEE Power Electronics Specialist Conference (PESC '05), June 2005. 

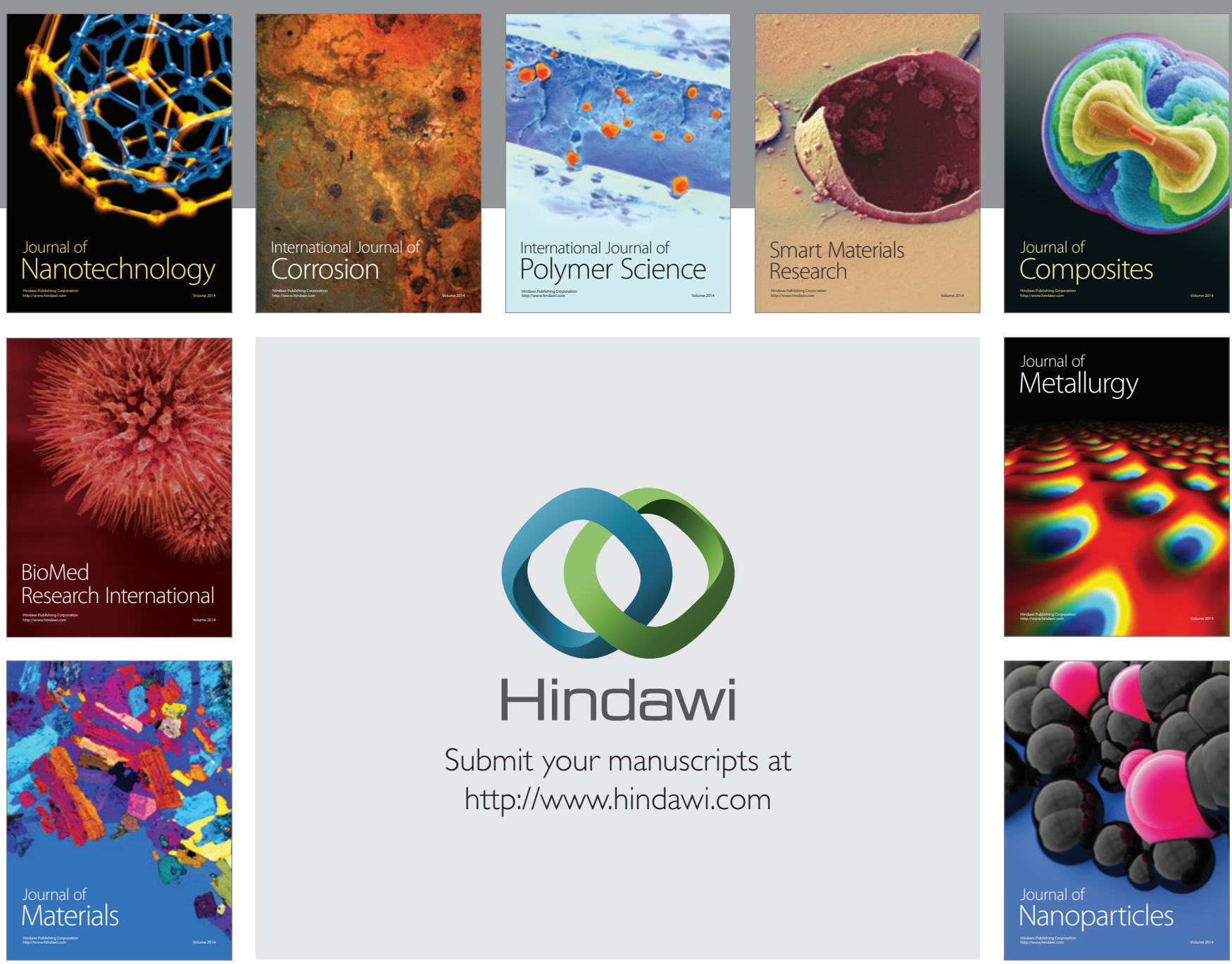

Submit your manuscripts at http://www.hindawi.com
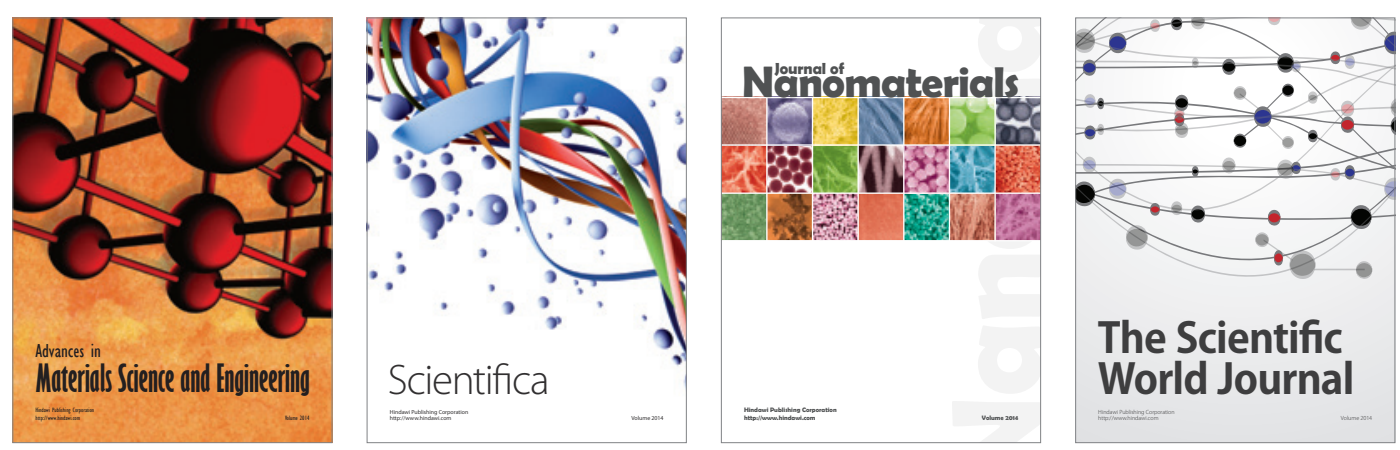

\section{The Scientific World Journal}
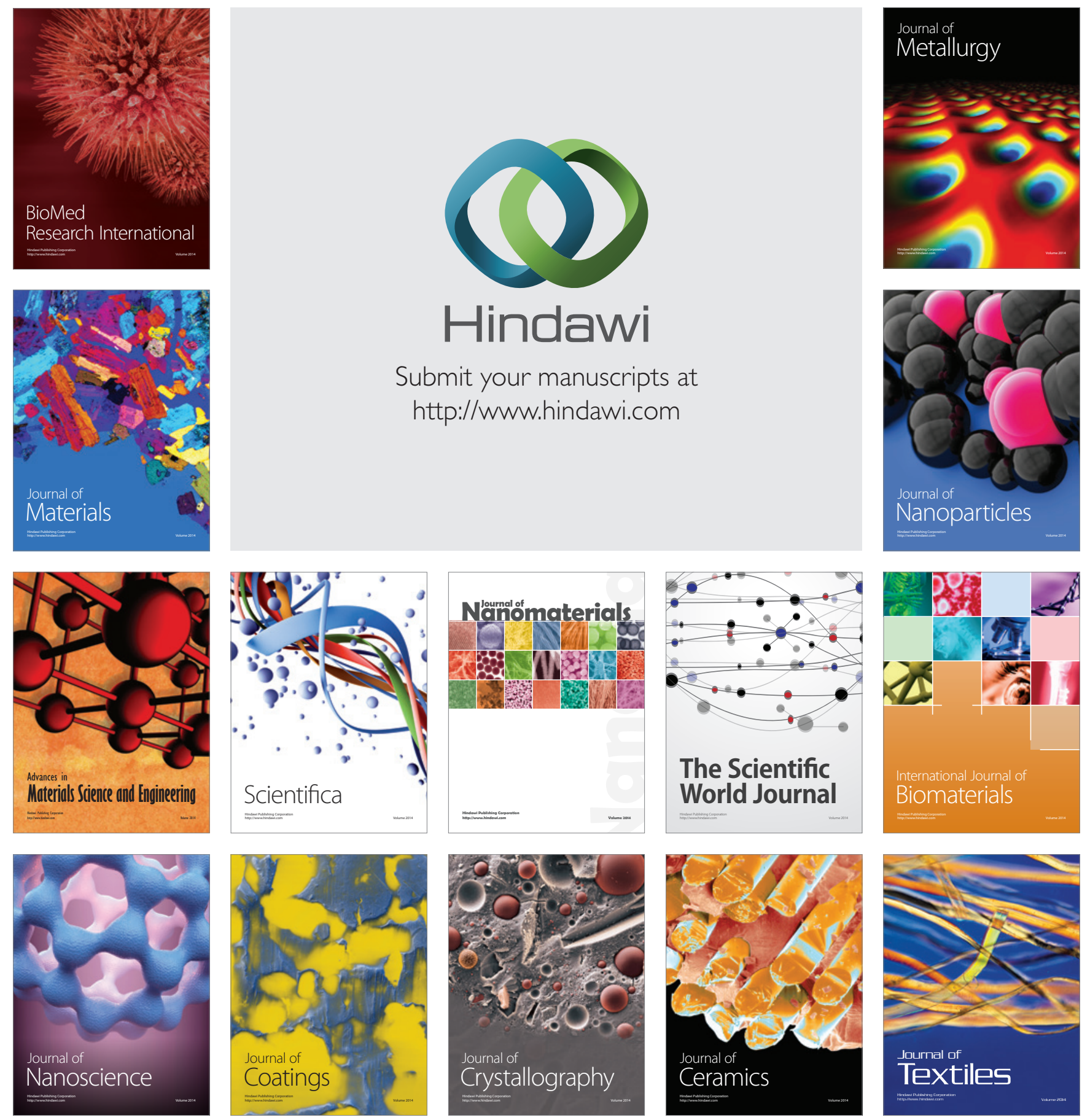